\title{
A Critical Review on Wind Turbine Power Curve Modelling Techniques and Their Applications in Wind Based Energy Systems
}

\author{
Vaishali Sohoni, S. C. Gupta, and R. K. Nema \\ Department of Electrical Engineering, Maulana Azad National Institute of Technology, Bhopal 462051, India \\ Correspondence should be addressed to Vaishali Sohoni; vaishalisohonibpl@gmail.com
}

Received 27 March 2016; Revised 8 June 2016; Accepted 12 June 2016

Academic Editor: Kamal Aly

Copyright (C) 2016 Vaishali Sohoni et al. This is an open access article distributed under the Creative Commons Attribution License, which permits unrestricted use, distribution, and reproduction in any medium, provided the original work is properly cited.

Power curve of a wind turbine depicts the relationship between output power and hub height wind speed and is an important characteristic of the turbine. Power curve aids in energy assessment, warranty formulations, and performance monitoring of the turbines. With the growth of wind industry, turbines are being installed in diverse climatic conditions, onshore and offshore, and in complex terrains causing significant departure of these curves from the warranted values. Accurate models of power curves can play an important role in improving the performance of wind energy based systems. This paper presents a detailed review of different approaches for modelling of the wind turbine power curve. The methodology of modelling depends upon the purpose of modelling, availability of data, and the desired accuracy. The objectives of modelling, various issues involved therein, and the standard procedure for power performance measurement with its limitations have therefore been discussed here. Modelling methods described here use data from manufacturers' specifications and actual data from the wind farms. Classification of modelling methods, various modelling techniques available in the literature, model evaluation criteria, and application of soft computing methods for modelling are then reviewed in detail. The drawbacks of the existing methods and future scope of research are also identified.

\section{Introduction}

Wind energy has emerged as a promising alternative source for overcoming the energy crisis in the world. Wind power based energy is one of the most rapidly growing areas among the renewable energy sources and will continue to do so because of the growing concern about sustainability and emission reduction requirements. The uncertain nature of wind and high penetration of wind energy in power systems are a big challenge to the reliability and stability of these systems. To make wind energy a reliable source, accurate models for predicting the power output and performance monitoring of wind turbines are needed. The theoretical power captured $(P)$ by a wind turbine is given by [1]

$$
P=\frac{1}{2} \rho A_{w} C_{P}(\lambda, \beta) v^{3} \text {. }
$$

The power production of a wind turbine (WT) thus depends upon many parameters such as wind speed, wind direction, air density (a function of temperature, pressure, and humidity) and turbine parameters [2]. Much complexity is involved in considering the effects of all the influencing parameters properly. It is therefore difficult to evaluate the output power using the theoretical equation given above. Power curve of a wind turbine, which gives the output power of turbine at a specific wind speed, provides a convenient way to model the performance of wind turbines. A typical power curve for a pitch regulated wind turbine is shown in Figure 1. In the first region when the wind speed is less than a threshold minimum, known as the cut-in speed, the power output is zero. In the second region between the cut-in and the rated speed, there is a rapid growth of power produced. In the third region, a constant output (rated) is produced until the cut-off speed is attained. Beyond this speed (region 4) the turbine is taken out of operation to protect its components from high winds; hence it produces zero power in this region. 


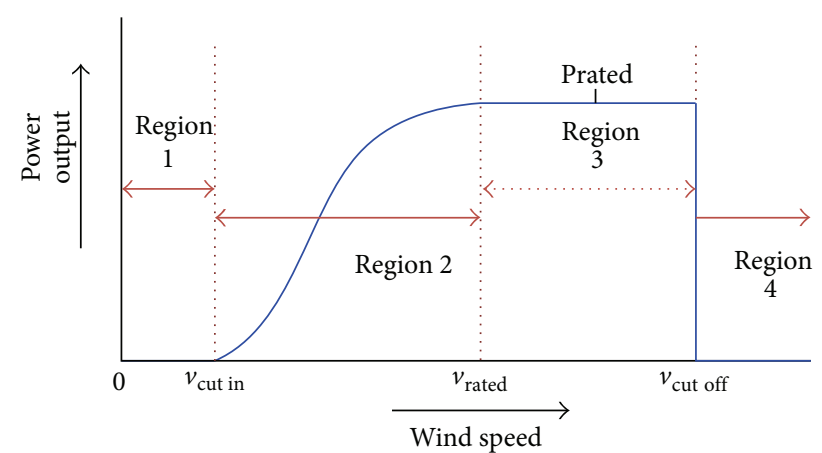

FIGURE 1: Typical power curve of a pitch regulated wind turbine.

The power curve of a WT indicates its performance. Accurate models of power curves are important tools for forecasting of power and online monitoring of the turbines. A number of methods have been proposed in various works to model the wind turbine power curve. These methods which use data from manufacturers' specifications and actual data from the wind farms have been utilized by many researchers in various wind power applications $[3,4]$. The literature reviewed reveals that appropriate selection of power curve models can help in improved performance of wind energy based systems. This paper presents current status of research and future directions of different wind turbine power curve modelling approaches. The need of modelling, modelling methodology, classification of models, and methods of evaluation have been discussed. The impact of various parameters on these curves, the standard procedure for power performance measurement of wind turbines, and the need for developing site specific curves is also discussed. Various models proposed and used in various studies have been compared critically and finally inferences are drawn.

\section{Need of Power Curve Modelling}

The power curve reflects the power response of a WT to various wind speeds. Accurate models of the curves are useful in a number of wind power applications. The objectives of modelling the wind turbine power curve have been discussed here.

2.1. Wind Power Assessment and Forecasting. The WT power curve can be used for wind power assessment. Wind resource assessment of a region in terms of wind speed, wind power density, and wind energy potential is done to identify areas suitable for wind power development [3]. In this process, estimation of energy is done by using the available wind data and wind turbine power curve. Predicting the output power of the turbine at a candidate site is also required in sizing and cost optimization studies during the design stage of a wind energy based system. The accuracy in power prediction is important as an overestimation can result in poor reliability and an underestimation can lead to oversizing of the wind energy conversion system. Wind turbine operators who trade energy directly to the electricity market also need to forecast the power output of their turbines accurately, so that they will be able to deliver the traded amount of power [2].
Power curves are supplied by the manufacturers in a tabular or graphical form. However, a generic equation which represents this curve accurately is required in various problems of wind power systems. Derivation of an appropriate function to describe the actual shape of the curve is a very important task. However, the manufacturer's curves are created under standard conditions therefore they may not represent the realistic conditions of the site under consideration. The turbine performance at the wind farms is also not ideal due to wear and tear and aging of turbines. Another method to model the power curves is to derive them using the actual data of wind speed and power measured from the turbines [4]. The data of wind turbines collected by the SCADA (supervisory control and data acquisition) system can be utilized for this purpose. This method can incorporate the actual conditions at the wind farms, thus providing better accuracy in power prediction.

2.2. Capacity Factor Estimation. The capacity factor of a WT is defined as the ratio of the average power output to the rated output power of the generator and is an indicator of its efficiency [5]. It is used to estimate the average energy production of a WT required for the sizing and cost optimization studies, optimum turbine-site matching, and ranking of potential sites $[5,6]$. The wind turbine power curve models are used to estimate the capacity factor of a WT. A comparative analysis of four power curve modelling methods in estimation of capacity factor of wind turbine generator is presented in [7].

2.3. Selection of Turbines. The power curve can be used to make generic comparison between models and can aid in the choice of turbine from the available options. The selection of the turbine characteristics which match with the wind regime of the site helps in optimizing the efficiency of wind energy system [8].

2.4. Online Monitoring of Power Curves. Power curves can be used for monitoring the performance of turbines. For this, a benchmark curve which represents the performance of a normally operating turbine is required. This reference curve can be extracted from measured power output and wind speed data of wind turbines. The actual curve of the turbine to be monitored can be compared with this benchmark curve. The deviations of the actual values from the expected output can indicate underperformance or faults [1]. The wind power output of a turbine can be affected by underperformance or various faults/anomalies of the turbine such as blade faults and yaw and pitch system faults [4, 9]. Different types of faults affect the turbine system differently and will cause the power curve to depart from the expected value in a different way. Tools which can characterize and quantify these departures can aid in early identification of faults. Statistical analysis of the outlier data can give indications of the specific reason of anomaly. Wind turbine condition monitoring by use of power curve copula modelling is suggested in $[10,11]$ and is a topic of further research. Early recognition of the emerging faults and timely repair and maintenance of the equipment can help in improving the performance of wind turbines. 


\section{Modelling Issues}

A number of aspects require consideration while modelling the power curves of wind turbines. The selection of model and methodology adopted depends upon the purpose of modelling, available data, impact of various parameters on these curves, and other related issues.

The following important issues should be taken into consideration while modelling of the power curve.

3.1. Difference in Models. The power curves vary with different manufacturers and models. Therefore the model used to describe them should also be different [12]. Also, there is difference between pitch regulated and stall regulated turbines. Pitch regulated turbines maintain constant output from the rated to cut-off speed, whereas the stall regulated turbines have a decreased power output above the rated wind speeds (stall region).

3.2. Cut-In and Cut-Off Behaviour. The turbine behaviour near cut-in and cut-off wind speeds can be difficult to model [8]. These limits are different for different turbine models. When the power curve is derived using the measured data, some nonzero and negative values of power outputs below cut-in speed can be obtained. The cut-off hysteresis which occurs during the period between shut down and restart of turbine affects the productivity of turbine [13]. Hysteresis effects can be more significant with certain wind patterns and terrains such as unsteady and gusty winds requiring frequent starting and shutting down, resulting in considerable loss of energy production. Power curve correction which takes into account this behaviour of turbine at cut-off can reduce the power prediction errors.

3.3. Single versus Group of Turbines. The manufacturers' curves are suitable for predicting the power output of a single turbine of a specific type. In a big wind farm a number of turbines are spread over a wide area. Wind energy production involves uncertainties due to stochastic nature of the wind and variation of the power curve [14]. The speed and direction of wind encountered by the turbines of a wind farm may not be the same due to variation of wind. Hence, in a wind farm, power produced by turbines with identical specifications can also differ, even if the wind speed is the same. The shadowing effect of turbines causes this difference as the turbines which operate in wake of other turbines may get reduced wind speeds [15]. This difference can also happen due to factors such as wear and tear, aging, and dirt or ice deposition on blades. With the growth of wind energy projects it has become essential to develop methods to monitor the performance of not only a single turbine but also the wind farm as a whole. Therefore building appropriate models to obtain the relationship between wind speed and output power when a group of turbines are deployed on a wind farm is required.

3.4. Influencing Factors. A number of factors can cause the power curve to deviate from the theoretical value $[1,2]$. The important influencing factors are given here and need due attention during modelling.

(i) Wind Conditions at the Site. Wind is highly stochastic in nature. The wind speed and direction change continuously. The wind at a particular site is affected by weather phenomena and topology of the site. The turbulence of wind at a given location affects the power production [16]. Obstacles like trees, buildings, and other high structures influence the wind.

(ii) Air Density. The pressure, temperature, and humidity of site affect the air density [17], hence affecting the power produced. Effect of varying air density has been considered for developing site specific curves [18]. It is shown in [2] that temperature has the highest influence on air density and considering its effect along with the wind direction resulted in improved performance of models.

(iii) Extrapolation of Wind Speed. The wind speed changes with height. This wind shear effect is affected by the roughness of terrain. The power curve uses the wind speed measured at the hub height of turbine, but this height varies with different models and manufacturers, and it is not always possible to measure the wind speed at this height. A number of methods have been used in the literature to express the variation of wind speed with height [12]. Also the wind speed measured at the masts is different from the speed at the turbine location and sometimes when the wind speed values at the particular site are not available the wind speed measurements from a nearby location are used to determine the wind profile of this site. The accuracy of conversion of the measured wind speed to wind speed at hub height and at the turbine location depends on factors such as the vertical wind profile at the site, position of masts relative to the turbine, and the method used for extrapolation.

(iv) Turbine Condition. The power curve is affected by the condition of turbine and associated equipment. Aging and wear and tear of turbine, anomalies and faults, blade condition, yaw and pitch misalignments, controller settings, and so forth cause the power curve to depart from actual values $[1,11]$.

3.5. IEC 61400-12-1 Standard [19]. IEC 61400-12-1, the commonly adopted international standard for power performance measurement, is found to be of relevance. The procedure for measuring the power performance characteristics of single wind turbines is specified in this standard. It is the most accepted standard for power curve measurement of single wind turbines. The standard describes the measurement methodology for the measured power curve which is determined by simultaneous measurement of wind speed and power output at the test site. A previous site calibration is required for certain terrain conditions. The annual energy production is calculated by applying the measured power curve to reference wind speed frequency distributions supplemented by sources of uncertainty and their effects. The standard prescribes derivation of power curve using the hub height wind speed measured with a cup anemometer in the 
suitable measurement sector, but if the wind speed has a large variation over the rotor swept area then there can be a significant difference between the hub height wind speed and wind speed averaged over the whole rotor swept area. The measurement methods and accuracy of measuring instruments can cause variance in measurements and can lead to large prediction errors. The impact of other measurement options such as consideration of rotor equivalent wind speed in which speed is measured at heights over the full rotor plane with the use of remote sensing technology (LIDAR and SONAR) and nacelle based anemometry is a topic of further research [20].

The IEC standard uses ten-minute averaged data grouped into wind speed intervals of $0.5 \mathrm{~m} / \mathrm{s}$ (method of bins). This 10-minute averaging of data introduces systematic averaging errors and short wind fluctuations are killed off. Wind at a specific site can be affected by a number of factors such as topology of the site and obstacles and weather phenomena. Although the IEC power curve considers the wind condition of the current site it may not always be appropriate to apply to the wind conditions of other sites. Research efforts are therefore required to develop site specific power curves. These curves can incorporate the wind conditions of the particular site, thus giving better results $[18,19]$.

Appropriate selection of modelling method is an important requirement for during planning and operation stage of wind based system and helps in improving the performance of the system. The methods which consider only wind speed as input may not take into account the variance caused by various influencing parameters. Methods which consider the influence of these parameters on the power curve can result in more accurate models. Wind at a specific site can be affected by a number of factors such as topology of the site and obstacles and weather phenomena. It is shown in [18] that the use of developed site power curves, which used the knowledge of site and turbine parameters for modelling, resulted in more accurate energy assessment than the turbine power curve. The issues discussed above if addressed properly can result in efficient models of power curves.

\section{Wind Speed Modelling}

Wind power generated is highly correlated with the wind speed distribution across the region where the wind farm is situated and depends upon the type of WT deployed in the wind farm. The accuracy in prediction of wind energy can be achieved by modelling the wind speed and power simultaneously. The wind speed at a site varies randomly and its variation in a certain region over a period of time can be represented by different probability distribution functions (PDF). Selection of appropriate PDF to describe the actual wind speed distribution of the site is crucial for accuracy in power prediction.

The most commonly used and accepted distribution is the two-parameter Weibull distribution [5, 21]. It is a versatile PDF, is simple to use, and is found to be accurate for most of the wind regimes encountered in nature. However, Weibull distribution is not suitable for certain wind regimes, for example, those having high frequencies of null winds, and

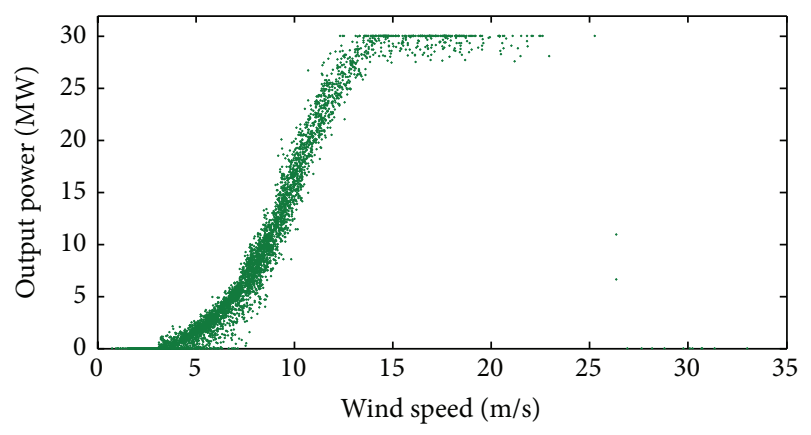

FIGURE 2: Power curve using actual data for a group of wind turbines at a wind farm (NREL) [66].

for short time horizons $[1,22]$. The Weibull PDF is given by

$$
f(v)=\frac{k}{c}\left(\frac{v}{c}\right)^{k-1} \exp \left(-\frac{v}{c}\right)^{k}
$$

Another widely used distribution is Rayleigh PDF [18] in which the shape parameter of (2) is taken as $k=2$. It is a simple PDF and can describe the wind regime with sufficient accuracy when little detail is available about the wind characteristics of a site. The wind speed distribution has also been described in the literature using several other PDFs which include lognormal, beta, and gamma distributions [23]. A detailed review of different PDFs for wind speed modelling and techniques for estimation of their parameters is given in [22]. Appropriate PDF and parameter estimation technique should be selected for modelling the wind speed for a particular site.

\section{Power Curve Models Classification}

The power curve modelling methods can be classified into discrete, deterministic/probabilistic, parametric/nonparametric, and stochastic methods or they can be classified on the basis of data used for modelling.

5.1. Discrete Models. In this method as described in IEC $61400-12$ all the wind speeds are discretized into $0.5 \mathrm{~m} / \mathrm{s}$ bins [19]. The power output for each bin is then modelled. This is a simple method as it does not require mathematical functions for describing the curve. Also it takes into account the nonlinear wind speed-power output relation. However a large number of data are required in this method to develop a reliable model.

5.2. Deterministic and Probabilistic Models. A deterministic power curve model assumes a fixed relation between the output power and wind speed. But when a fleet of wind turbines are deployed on a wind farm, turbines of the same type may produce different amount of power even if the wind speed is the same (Figure 2). A probabilistic power curve model incorporates these power variations to characterize the relationship between wind speed and actual output powers. Most of the models available in the literature are of deterministic nature and are constructed by using the manufacturers' 
power curve data. A probabilistic model proposed in [14] characterizes the dynamics of output power by a normal distribution with varying mean and constant standard deviation. The method given in the paper accommodates the uncertainty of output power. The probabilistic nature of wind power output can also be modelled by deriving curves using actual data of power output and wind speed of turbines deployed in a wind farm. This method requires a large number of historical data but results in accurate models $[4,24]$.

5.3. Parametric and Nonparametric Models. A parametric model defines the relationship between input and output by a set of mathematical equations with a finite number of parameters. In a nonparametric model, no assumption is made about the functional form of the phenomenon under observation. Parametric models of WT power curve can be built by utilizing a set of mathematical expressions having a fixed number of parameters, which are usually collected together to form a single parameter vector $\theta=$ $\left(\theta_{1}, \theta_{2}, \theta_{3}, \ldots, \theta_{n}\right)$. Nonparametric models are used when it is difficult to define the underlying theory upon which the parametric model can be constructed [24].

5.4. Models Based on Presumed Shape, Curve Fitting, and Actual Data. The models of power curves can be classified according to the data being used for modelling. Models of power curve based on presumed shape of curve utilize only the cut-in, cut-off, and rated speeds and the rated power of the selected turbine for calculating the parameters of expressions used in the model $[12,25,26]$. These ratings are available from the specifications of the turbines. When the manufacturer's power curve data is available, models can be developed by fitting one or more appropriate expressions to the actual curve. The parameters of the expression being fitted to the actual curve are generally calculated by using the least squares method [4]. The models derived from actual data of wind farm need the actual wind speed and power output data from an operational wind farm. If the effect of the influencing parameters is also included in the model, then the data of the included parameters is also required. This data can be obtained from the wind farm's SCADA system.

5.5. Stochastic Models. The stochastic method consists of characterizing the power performance of wind turbine by evaluating dynamic response against the fluctuating wind speed inputs $[27,28]$. The dynamic power output is separated into a deterministic stochastic part in this model. In [29] the Markov chain theory is used to describe the power output of WT. The resulting model is independent of turbulence intensity; however, the effect of other influencing parameters is not taken into account in this method.

\section{Power Curve Modelling Approaches}

Various approaches have been used in the literature for modelling of WT power curve. These methods, their merits, limitations, and application areas are discussed here.
6.1. Parametric Models. The power delivered by a WT can be expressed as

$$
P= \begin{cases}0 & v<v_{c}, v>v_{f} \\ q(v) & v_{c}<v<v_{r} \\ P_{r} & v_{r} \leq v \leq v_{f} .\end{cases}
$$

The relationship between power output and wind speed of a WT between cut-in and rated speed is nonlinear (region 2 of Figure 1). The relation $q(v)$ can be approximated by various functions using polynomial and other than polynomial expressions. The pitch regulated turbines maintain a constant power output in region 3 of Figure 1, whereas the stall regulated turbines have decreased power output in this region; thus the power in this region for a stall regulated turbine should not be modelled as a constant. The governing equations for different approximations of power curve are given in Table 1.

6.1.1. Polynomial Function Approximation. The nonlinear wind speed-power relationship, $q(v)$, can be approximated by various polynomial expressions. Different models using linear, quadratic, cubic, and higher powers of speed or their combinations have been used in the literature.

(i) The most simplified model based on a linear curve, which describes region 2 of power curve by a straight line, is used in many applications [12, 39-42].

(ii) A quadratic model represents the nonlinear portion of the curve by an equation of degree 2. $q(v)$ has been approximated by a quadratic equation in [25] to describe the relation between output power and wind speed of a WT. A binomial expression discussed in [30] has been adopted by many researchers $[43,44]$ to determine output power of wind turbines. Regions 2 and 3 of Figure 1 for a stall regulated WT can be described by using two different binomial expressions as in [45].

(iii) Model based on cubic law approximates region 2 of power curve by cubic law. A model which describes the nonlinear power-wind speed relationship by a cubic law is discussed in [46]. This model is used for power output calculations in [26,31,47]. A cubic expression for region 2 and a linear expression for region 3 are chosen to describe the power curve in [48].

The models given above use the WT specifications of rated power and cut-in, cut-off, and rated wind speed only to determine the equations for power curve.

(i) A methodology based on Weibull's parameter is proposed in [6]. This model based on Weibull shape parameter is used by many researchers $[49,50]$ for calculating the power output of WT.

(ii) A linearized segmented model discussed in $[24,51]$ carries out a piecewise linear approximation of the 
TABLE 1: Expressions of parametric models.

\begin{tabular}{|c|c|c|}
\hline Model & Expressions of $P$ and $q$ & Parameters \\
\hline Linear $[12]$ & $q(v)=P_{r} \frac{\left(v-v_{c}\right)}{\left(v_{r}-v_{c}\right)}$ & - \\
\hline Quadratic [25] & $q(v)=P_{r}\left(\frac{v-v_{c}}{v_{r}-v_{c}}\right)^{2}$ & 5 \\
\hline Binomial [30] & $q(v)=\left(a+b v+c v^{2}\right) P_{r}$ & $\begin{array}{l}a=\frac{1}{\left(v_{c}-v_{r}\right)^{2}}\left[v_{c}\left(v_{c}+v_{r}\right)-4 v_{c} v_{r} \frac{\left(v_{c}-v_{r}\right)^{2}}{2 v_{r}}\right] \\
b=\frac{1}{\left(v_{c}-v_{r}\right)^{2}}\left[4\left(v_{c}+v_{r}\right) \frac{\left(v_{c}-v_{r}\right)^{3}}{2 v_{r}}-3\left(v_{c}+v_{r}\right)\right] \\
c=\frac{1}{\left(v_{c}-v_{r}\right)^{2}}\left[2-4 \frac{\left(v_{n}+v_{r}\right)^{3}}{2 v_{r}}\right]\end{array}$ \\
\hline Cubic [31] & $q(v)=a v^{3}-b P_{r}$ & $\begin{array}{l}a=\frac{P_{r}}{\left(v_{r}^{3}-v_{c}^{3}\right)} \\
b=\frac{v_{r}^{3}}{\left(v_{r}^{3}-v_{c}^{3}\right)}\end{array}$ \\
\hline Weibull based [6] & $q(v)=a+b v^{k}$ & $\begin{array}{l}a=\frac{P_{r} v_{c}^{k}}{\left(v_{c}^{k}-v_{r}^{k}\right)} \\
b=\frac{P_{r}}{\left(v_{c}^{k}-v_{r}^{k}\right)}\end{array}$ \\
\hline Double exponential [32] & $P=\exp \left(-\tau_{1} \exp \left(-v \tau_{2}\right)\right)$ & $\tau_{1}$ and $\tau_{2}$ to be estimated \\
\hline $4 \mathrm{PL}[1,33]$ & $P=a\left(\frac{1+a m e^{v / \tau}}{1+a m e^{v / \tau}}\right)$ & 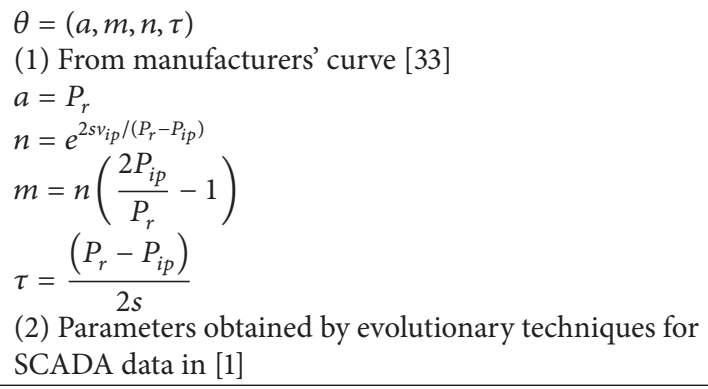 \\
\hline $4 \mathrm{PL}[34,35]$ & $P=f(v, \theta)=D+\frac{(A-D)}{1+(v / C)^{B}}$ & $\begin{array}{l}\theta=(A, B, C, D) \\
A=\text { minimum asymptote } \\
B=\text { Hill slope } \\
C=\text { inflection point (point of curve where the curvature } \\
\text { changes direction) } \\
D=\text { maximum asymptote } \\
\text { (parameters obtained by evolutionary techniques) }\end{array}$ \\
\hline $5 \mathrm{PL}[24,35,36]$ & $P=f(v, \theta)=D+\frac{(A-D)}{\left(1+(v / C)^{B}\right)^{G}}$ & $\begin{array}{l}\theta=(A, B, C, D, G) \\
A=\text { minimum asymptote } \\
B=\text { Hill slope } \\
C=\text { inflection point (point of curve where the curvature } \\
\text { changes direction) } \\
D=\text { maximum asymptote } \\
G=\text { asymmetry factor } \\
\text { (parameters obtained by evolutionary techniques) }\end{array}$ \\
\hline
\end{tabular}

curve by using the equation of a straight line. The resulting curve follows the actual curve more accurately.

(iii) The power curve of wind turbine has also been modelled by other than polynomial functions. The power curve that is modelled in [52] uses a exponential equation whereas a double exponential equation is used in [32]. (iv) A polynomial regression parametric model is developed from real data as a benchmark method in [53]. Three nonparametric methods are also proposed in this study.

6.1.2. Approximations Considering Inflection Point on the Curve. All the polynomial expressions given above do not take into account the inflection point on the power curves. 
In most real power curves there is an inflection point on the curve at which its curvature changes sign. Models which consider this inflection point can describe the actual shape of the curve more accurately than the above models. A new formula for power curve interpolation which considers inflection point on the curve is proposed in [54]. A double exponential model is proposed in [32] to fit the data in two inflection zones using a single equation. Functions based on four- and five-parameter logistic approximations also consider this inflection point on the curve and are promising approaches for modelling of power curve.

(i) The shape of a wind power curve can be approximated by a four-parameter logistics (4PL) function [1,34]. A procedure to obtain the parameters of the $4 \mathrm{PL}$ function model modelled from manufactures power curve data has been proposed in [33]. The four parameters of the function are obtained directly from the power curve instead of using an optimization process in this work. The paper also proposes manufacturer's power curve approximation using a three-parameter model. The power curve is derived from the SCADA data of wind farms using a $4 \mathrm{PL}$ approximation in $[1,4,24]$. It is shown in [1] that this model can be used for online monitoring of power curves. Another form of four PL expression is used for extracting power curve from actual wind speed and power curve data of a wind farm in [35]. The method is applied for wind energy estimation of the selected wind farm site. Literature reviewed reveals that the four-PL model produces less errors in representing the power curve than the methods based on polynomial approximation. However a $4 \mathrm{PL}$ curve is symmetric about the inflection point whereas the power curves are asymmetric. Models which can incorporate this asymmetry can therefore produce even better results. Cubic splines can be used for asymmetric data. A cubic spline is the smoothest curve that passes through the exact data points. As the power curves are quite smooth their asymmetry can be approximated by a cubic spline interpolation technique [55-57], but the disadvantage with a spline fit is that it does not represent the random variation of data.

(ii) A five-parameter logistic (5PL) approximation includes a fifth parameter ( $G$ in Table 1) to control the degree of asymmetry [58]. This method can model the asymmetry effectively and can be used for modelling the WT power curve [36]. A 5PL model however has the possibility of becoming ill-conditioned; thus evaluation of parameter vector becomes difficult. A 5PL model derived from the SCADA data of wind farm is applied for energy estimation of the farm in [35] and it is shown that it produces less error in the estimated energy compared to the 4PL model.

6.1.3. Model Based on Curve Fitting of Manufacturer's Curve. The power curve models obtained by means of curve fitting of the manufacturer's curve are used in several applications. The characteristic equation of wind generator is fitted with three binomial expressions for $q(v)$ in [59] to get the accuracy in fitting. A ninth-order polynomial for power curve fitting has been used in [60] and it has been found that it gives accurate correlation with the real data, producing exclusively positive values for the generated power between cut-in to cutoff range. High-order polynomials may produce better fitting results for a particular set of data; however they may not represent the variance of data and should be used carefully. The power curve models by curve fitting of the manufacturer's curve are analyzed in [55-57].

6.2. Parameter Estimation. The parametric models of WT power curve express the shape of the curve by a set of mathematical equations. Determination of the coefficients of these equations requires fitting the data to the selected model. The techniques and algorithms used in various works for parameter estimation of power curve models are discussed here.

\subsubsection{Techniques for Parameter Estimation}

(i) Least Squares Method. The least squares method minimizes the summed square of residuals to obtain the parameters of the model and is the most commonly used and accepted method [4, 24].

(ii) Maximum Likelihood Method (MLM). Another approach used in the literature is to determine the parameters of power curve model by maximum likelihood method. In this method the parameters of a statistical model are estimated by maximizing the likelihood function. It was found in [1] that this method did not perform well in comparison to the least squares method.

6.2.2. Algorithms for Parameter Estimation. The parameters of the parametric models especially those using the 4PL and 5PL approximations are difficult to evaluate. The parameter estimation becomes more difficult when the models are derived from the actual data of wind turbines. Developing accurate models of wind turbines and optimization for huge data sets are a very complicated process. Modern nontraditional solution techniques for parameter estimation enhance the accuracy, reduce the computational time, and are easy to implement. Various evolutionary techniques have been applied for determining the parameter vector $\theta$ of logistic function based power curve models $[4,24]$.

6.3. Data Preprocessing. The power curve derived from actual wind speed and power output data of wind turbines uses SCADA data from the wind turbines. This data is prone to errors due to measurement, sensor, and communications system errors. The data is also affected by nonproduction of turbines when it is shut down by the control system for some reason other than anomalous operation. SCADA system can have null entries or erroneous data which can result in inaccurate models. Hence it is necessary to remove these misleading entries before using this data for further analyses. The most common method is to remove the data manually. These outliers can be identified by visual inspection [11] of wind speed power output plot and can be removed before 
proceeding for development of model. However the method can lead to inaccurate results as the data from SCADA system is voluminous and it is difficult to differentiate between correct and erroneous data. These outliers have been removed by different statistical methods in various works before development of models. In [4] the analysis of residuals together with control charts is used to filter potential outliers. The outliers can be detected by classical least mean square (LMS) method which minimizes the sum of the squares over all the measurements and if a measurement is found to be far away from the correct value it prevails in the resulting fitting; however, in this method a single outlier point can destroy the fitting. In [32] least median of squares method is used for data preprocessing in which instead of the sum as in LMS method sum of medians is minimized to identify the outliers. It is shown that this method is very robust; however it requires iterative solution. The wind data preprocessing is done in four steps in [63] which include validity check, data scaling, missing data processing, and lag removal. In [64] a probabilistic method developed around a copula-based joint probability model for power curve outlier rejection is proposed. A data mining approach to process the raw data has been proposed in [65]. Appropriate method for data preprocessing is important requirement for development of an efficient model.

6.4. Evaluation of Model. After developing the model from the data, it is important to determine whether this model appropriately represents the behaviour of the actual data for the power curve. The evaluation of the developed models in various applications is done on the basis of a number of performance metrics. The root mean square error (RMSE), goodness of fit statistics used by a wide number of researchers, estimates of the standard deviation of random component in the data, and a value closer to zero indicate a better fit. The $R$-squared statistic is the square of the correlation between the actual and the predicted values that measures how closely the fit explains variation in the data. An $R$-squared value closer to one indicates a good fit [38]. Other criteria used in the literature include the mean absolute error (MAE), mean absolute percentage error (MAPE), the sum of squares error (SSE), SD (standard deviation), and chi-square $R[2,4,8,11$, 17]. The most commonly used criteria are given in Table 2.

Selection of appropriate model analyzed on the basis of suitable criteria is a very important task for improving the performance of wind power plants. Many models used in the literature have not been evaluated for goodness of fit with actual curve data or their suitability for specific applications. The polynomial models of $[54,57]$ are compared by observing the visual fit. Models in $[2,11]$ are compared by MAE, RMSE, MAPE, and SD performance metrics; however, suitability of these models for wind power applications is not evaluated. Also as these models will ultimately be used in wind energy applications it is not appropriate to judge their suitability on the basis of goodness of fit parameters alone, but it should also be examined how successfully they can be employed for the particular applications.
TABLE 2: Model evaluation indices.

\begin{tabular}{|c|c|}
\hline & Expression \\
\hline $\begin{array}{l}\text { Absolute error (AE) } \\
{[1]}\end{array}$ & $\mathrm{AE}=\left|y_{m}(i)-y_{a}(i)\right|$ \\
\hline Relative error (RE) [1] & $\mathrm{RE}=\frac{y_{m}-y_{a}}{y_{a}} \times 100$ \\
\hline $\begin{array}{l}\text { Mean absolute error } \\
\text { (MAE) [24] }\end{array}$ & $\mathrm{MAE}=\frac{1}{N} \sum_{i=1}^{N}\left|y_{m}(i)-y_{a}(i)\right|$ \\
\hline $\begin{array}{l}\text { Mean absolute } \\
\text { percentage error } \\
\text { (MAPE) [37] }\end{array}$ & MAPE $=\frac{1}{N} \sum_{i=1}^{N}\left|\frac{y_{m}(i)-y_{a}(i)}{y_{a}(i)}\right|$ \\
\hline $\begin{array}{l}\text { Root mean square } \\
\text { error (RMSE) [24] }\end{array}$ & $\mathrm{RMSE}=\left[\frac{1}{N} \sum_{i=1}^{N}\left(y_{m}(i)-y_{a}(i)\right)^{2}\right.$ \\
\hline$R$-squared [38] & $R^{2}=1-\frac{\sum_{i=1}^{N}\left(y_{a}(i)-y_{m}(i)\right)^{2}}{\sum_{i=1}^{N}\left(y_{a}(i)-y_{a m}(i)\right)^{2}}$ \\
\hline
\end{tabular}

$N=$ number of data, $y_{m}(i)=i$ th modelled value, $y_{a}(i)=i$ th actual value, and $y_{a m}(i)=$ mean of actual value.

6.5. Nonparametric Models. Various nonparametric methods can be used for modelling of WT power curves. The SCADA data collected from the wind farms is voluminous and usually contains errors. It may be difficult to obtain the relation between input and output using a functional form. Nonparametric methods can be suitable for deriving power curves from this data. After preprocessing of data, model extraction can be done using different methods. Nonparametric models can also incorporate the effect of parameters other than wind speed on the power curves more easily than the parametric models. The models can be trained by taking these other parameters as inputs to the models $[17,18]$. Developments in soft computing techniques offer promising approaches for power curve modelling. Various advanced algorithms can be utilized to generate accurate nonparametric power curves for various applications. Table 3 summarises details of some nonparametric models from the literature.

6.5.1. Neural Networks. Artificial neural networks (ANN) inspired by biological nervous system emulate the natural intelligence of human brain [67] and can learn the nonlinear relationship between input and output data sets by use of activation function within the hidden neurons. Neural networks are used to estimate power generation of turbines at a wind farm in [17]. A separate multilayer perception (MLP) network for each turbine uses ten-minute averages of wind speed and direction from two meteorological towers as inputs and power generated by the turbine as the output. A comparative analysis of regression and ANN models for WT power curve estimation is done in [61] and it is shown that neural network models perform better than the regression models. However ANN has a black box approach and it is difficult to develop an insight about meaning associated with each neuron and weight [68]. ANN based multistage modelling has been used in [62] to model the wind turbine power curve. The wind speed and air density are used as inputs in the first stage and the normalized power output obtained from this stage, wind speed data turbulence intensity, is used to train the second ANN stage. It is claimed that this method has produced 
TABLE 3: Details of some nonparametric models from various studies.

\begin{tabular}{|c|c|c|c|c|c|c|}
\hline & & Data set & & & Model & \\
\hline Ref. & Interval & Data & $\begin{array}{l}\text { Number of } \\
\text { values }\end{array}$ & Model & Parameters & $\begin{array}{l}\text { Structure/transfer } \\
\text { function }(\mathrm{TF}) / \text { training } \\
\text { method }\end{array}$ \\
\hline$[4]$ & $10 \mathrm{~min}$ & $\begin{array}{l}\text { SCADA data } \\
100 \mathrm{WTs}\end{array}$ & $\begin{array}{c}\text { Total } 4347 \\
\text { Training } 3476 \\
\text { Testing } 871\end{array}$ & $k-\mathrm{NN}$ & $k=100$ & $\begin{array}{l}\text { Euclidian distance } \\
\text { metric }\end{array}$ \\
\hline [17] & $10 \mathrm{~min}$ & $\begin{array}{c}12 \mathrm{WTs} \\
\text { (wind speed and } \\
\text { direction from } \\
\text { two } \\
\text { meteorological } \\
\text { towers) }\end{array}$ & $\begin{array}{c}\text { Training } \\
1500 \text { patterns for } \\
\text { each WT }\end{array}$ & ANN & $\begin{array}{c}\text { Number of hidden layers } \\
=1 \\
\text { Number of hidden layer } \\
\text { neurons }=8\end{array}$ & $\begin{array}{l}\text { (i) Separate MLP } \\
\text { network for each WT } \\
\text { (ii) Training-pattern } \\
\text { mode } \\
\text { (iii) TF-hyperbolic (all } \\
\text { layers) }\end{array}$ \\
\hline [8] & - & $\begin{array}{l}\text { Measured data } \\
100 \mathrm{~kW} \text { WT }\end{array}$ & - & $\begin{array}{l}\text { Fuzzy } \\
\text { clustering }\end{array}$ & $\begin{array}{l}\text { Number of cluster } \\
\quad \text { centers }=8\end{array}$ & $\begin{array}{l}\text { (i) CFL } \\
\text { (ii) Subtractive } \\
\text { clustering }\end{array}$ \\
\hline \multirow{4}{*}{ [24] } & \multirow{4}{*}{$10 \mathrm{~min}$} & $\begin{array}{l}\text { Data set } 1 \\
\text { generated with } \\
\text { method in [9] }\end{array}$ & $\begin{array}{c}\text { Total } 1008 \\
\text { Training 50\% } \\
\text { Testing 50\% }\end{array}$ & \multirow{3}{*}{ ANN } & \multirow{3}{*}{$\begin{array}{c}\text { Number of hidden layer } \\
\text { neurons }=5\end{array}$} & \multirow{3}{*}{$\begin{array}{l}\text { (i) Feed forward back } \\
\text { propagation } \\
\text { (ii)Training: } \\
\text { Levenberg-Marquardt } \\
\text { (iii) TF: hidden layer } \\
\text { transig } \\
\text { (iv) TF: output layer } \\
\text { purlin }\end{array}$} \\
\hline & & Data set 2 & $\begin{array}{l}\text { Total } 4388 \\
\text { Training 50\% } \\
\text { Testing 50\% }\end{array}$ & & & \\
\hline & & $\begin{array}{l}\text { Data sets } 3,4, \\
\quad \text { and } 5\end{array}$ & $\begin{array}{l}\text { Total } 2208 \\
\text { Training 50\% } \\
\text { Testing 50\% }\end{array}$ & & & \\
\hline & & $\begin{array}{c}\text { Data sets } \\
1-5 \text { as above }\end{array}$ & As above & $\begin{array}{c}\text { Fuzzy } \\
\text { clustering }\end{array}$ & $\begin{array}{l}\text { Number of cluster } \\
\text { centers }=8\end{array}$ & Fuzzy $C$-means \\
\hline \multirow[b]{3}{*}{ [2] } & \multirow[b]{3}{*}{$10 \mathrm{~min}$} & \multirow{3}{*}{$\begin{array}{l}\text { SCADA (three } \\
\text { 2 MW WTs) } \\
\text { (model type 1: } \\
\text { wind speed } \\
\text { Model type 2: } \\
\text { wind speed and } \\
\text { direction, } \\
\text { temperature) }\end{array}$} & \multirow{3}{*}{$\begin{array}{c}32796 \\
\text { Training } 60 \% \\
\text { Validation } 40 \%\end{array}$} & $\begin{array}{l}\text { Fuzzy } \\
\text { clustering }\end{array}$ & $\begin{array}{c}\text { Number of cluster } \\
\text { centers } \\
\text { Type } 1=3 \\
\text { Type } 2=6\end{array}$ & CCFL \\
\hline & & & & $\begin{array}{l}\text { MLP } \\
\text { NN }\end{array}$ & $\begin{array}{l}\text { Number of hidden layers } \\
\qquad=2\end{array}$ & $\begin{array}{l}\text { (i) Training-gradient } \\
\text { descent } \\
\text { (ii) TF: hidden } \\
\text { layer-sigmoid } \\
\text { (iii) TF: output } \\
\text { layer-linear }\end{array}$ \\
\hline & & & & ANFIS & $\begin{array}{l}\text { Type } 1 k=150 \\
\text { Type } 2 k=3\end{array}$ & $\begin{array}{l}- \\
\text { (i) FIS structure Sugeno } \\
\text { type } \\
\text { (ii) Training-hybrid } \\
\text { learning } \\
\text { (iii) Membership } \\
\text { functions } \\
\text { Input space-generalized } \\
\text { normal } \\
\text { Output space-linear } \\
\text { (iv) Number of MFs = } 3\end{array}$ \\
\hline
\end{tabular}

better results compared to the parametric, nonparametric, and discrete models.

6.5.2. Clustering Methods. Clustering is grouping of similar data into classes or clusters. A wind farm having many wind turbine generators has variable power outputs due to variation of wind speed. Efficient power curve can be found by applying clustering methods. Power curve characterization by cluster centre, fuzzy $C$-means, and subtractive clustering methods is done in [69]. Fuzzy clustering applies the concept of fuzzy sets to cluster analysis and belongingness of each point of data set to a group is given by a membership function. The method has the advantage of adapting noisy data. Fuzzy C-means clustering uses fuzzy partitioning to partition a collection of vectors into $c$ fuzzy groups and finds a cluster 
centre $c_{i}$ in each group. The performance of FCM depends upon the initial cluster centres. The method proposed in [70] to decide the number of clusters and their initial values for initializing iterative optimization based clustering algorithms is used in [8] to set up cluster centre fuzzy logic (CCFL) model of power curve. This cluster estimation method is used as a basis for identifying fuzzy models and the effect of number of cluster centres and cluster neighbourhood distance on RMSE is calculated. On comparison of CCFL model with polynomial model fitted by least square method it is concluded that the RMSE obtained with the fuzzy logic method is much lower than that obtained with the least square polynomial model.

6.5.3. Data Mining. Data mining refers to extracting or mining knowledge from large amounts of data [71]. Developments in data mining offer promising approaches for modelling power curves of wind turbines. Selection of appropriate data mining method and algorithm is important to get accurate, stable, and robust power curve. Data driven nonparametric models using multilayer perception (MLP), random forest, M5P, boosting tree, and $k$-nearest neighbour $(k-\mathrm{NN})$ algorithms are developed in [1] along with the 4PL parametric models. Performance of these models for online monitoring of the power curves was analyzed and the least square 4PL parametric and $k$-NN models were found to be of high fidelity to be used as reference curves for monitoring of power curves. Control chart approach is used for detecting the outliers and indicating the abnormal conditions of the turbine. However in another study [2] the performance of $k$ $\mathrm{NN}$ was found to be poor. Different data mining algorithms, namely, MLP, REP tree, M5P tree, bagging tree, and $k$ nearest neighbour algorithms, are used to build models for power prediction and online monitoring in [4]. Principle component analysis and $k$-NN algorithm are used for data reduction and filtering of outliers is done by residual and control chart approach. In [2] four data mining techniques, namely, bagging, M5P algorithm, REP tree algorithm, and M5 rules, were used for constructing the nonparametric power curve models. Model trees are type of decision trees with linear regression functions at the leaves and are applied for modelling the power curves in a few applications [2, 24]. Much detail of these models is not given in these studies. More information on model trees can be found in $[72,73]$.

6.5.4. Adaptive Network-Based Fuzzy Inference System (ANFIS) Model. Adaptive network-based fuzzy inference system (ANFIS) is a fuzzy inference system implemented in the framework of adaptive networks and thus integrates the best features of fuzzy systems and neural networks [68]. A fuzzy inference system using fuzzy if-then rules is based on human knowledge and reasoning processes. In ANFIS, tuning of nonlinear signal relations can be done by constructing a set of fuzzy rules with appropriate membership function parameters tuned in a training phase [67]. Application of ANFIS for wind turbine power curve monitoring is proposed in [2]. This method of modelling is compared with earlier best performing methods, namely,
ANN, CCFL, and $k$-NN methods, found in the literature. Effect of including direction of wind and ambient temperature on the prediction error is evaluated. Data for pitch regulated turbines is used for the modelling.

6.5.5. Joint Probability of Wind Speed and Power. Another approach of modelling is to consider the joint probability distribution of power and wind speed instead of considering the implied function of the two variables. Considering joint probability of the two variables instead of their individual probabilities can incorporate measures of uncertainty into performance estimates [11]. SCADA wind speed and power measurement data from wind turbines are used to estimate bivariate probability distribution functions and construct power curve using copula modelling technique in [10]. The application of empirical copulas is proposed to approximate the complex form of dependency between active power and wind speed. Usefulness of copula analysis for turbine condition monitoring and early recognition of faults is suggested in this paper. It is shown that different fault modes produce different signatures in $R, R^{2}$, and chi ${ }^{2}$ statistics and can be used to identify the type of turbine fault.

6.5.6. Wavelet Support Vector Machine. Wavelet analysis is a technique to analyze the nature of signals and is a promising tool for nonstationary signals. In support vector machines the data is mapped into higher-dimensional feature space via nonlinear mapping. The power curve of WT is used for wind power prediction in [37]. A novel wavelet support vector machine based model for wind speed prediction is proposed in this paper and its performance is found to be effective for short time prediction.

A number of works in literature also include comparative analyses of various parametric and nonparametric methods $[2,8,57,74]$. Seven different functions have been compared in [75] for modelling the power curves of six different turbines. In [53] four models are developed from available operational power output data. The polynomial regression based parametric model is used as a benchmark model. Three nonparametric methods in addition to the above methods, namely, locally weighted polynomial regression, cubic spline regression, and a penalized spline regression model, are proposed in this study.

\section{Selection of Modelling Method}

A number of models and modelling methodologies have been proposed in various works for modelling of WT power curve. The choice of appropriate model and methodology adopted for a specific application is important and is a difficult task. The model selection for a particular application is done on the basis of availability of data, complexity of model, desired accuracy, and type of turbine and its power curve. On the basis of reviewed literature the following points are identified for selection of modelling methodology.

(i) Wind power curve models required for initial wind resource assessment need handy methods for estimation of energy. Wind power output calculation and 
energy estimation which are done during designing of wind based systems need a power curve model with fair degree of accuracy. When only specification values (cut-in, cut-off, and rated speeds and the rated power) for a wind turbine are available, the polynomial models based on presumed shape can be used. These models can also be used as a handy tool for calculation of wind turbine output during design stage of wind farms because of the simplicity of calculations. When the manufacturers' curve data is available it is preferable to fit a polynomial function to the data as it results in better accuracy. These models are thus suitable for modelling of single turbines for predicting power for small systems where fairly accurate accuracy is desired.

(ii) For power prediction and selection of turbines for designing of large wind based systems a very good accuracy is required as oversizing can result in loss of revenue and undersizing can hamper the reliability of the system. Accurate prediction is also required for wind farm operators for energy trading. The $4 \mathrm{PL}$ and 5PL functions may therefore be used for these applications to develop models from the manufacturers' curve data.

(iii) When the SCADA data from a nearby wind farm is available and it is desired to assess the power output of a prospective wind farm with good accuracy having a group of turbines or when the models is to be used for online monitoring of curves, it is appropriate to extract model from SCADA data of the wind farm with appropriate extrapolations. These models can be derived using the 4PL and 5PL parametric methods or one of the nonparametric methods such as ANN or ANFIS. The models can also incorporate the effect of other influencing parameters in the models. Choice of parameters depends upon terrain, wind conditions, obstacles, correlation of parameters, and so forth. The copula method of defining the power curve using a joint probability distribution function of wind speed and power can be used for condition monitoring applications.

\section{Discussions and Prospects}

Various methods of modelling of WT power curve have been reviewed. Several methods of modelling have been proposed and used in various studies (Figure 3). A summary of noteworthy contributions is given in Table 4 . The salient features of these models are summarised in Table 5. The inferences drawn, the deficiencies, and the suggestions proposed are given below.

(i) Most of the parametric models used in the literature use polynomial approximations to model wind power curve models. These models are mostly used for predicting power output of turbines for sizing and cost optimization applications. These models do not consider the inflection point on the power curve accurately and can result in large prediction errors.
However they are simple to use and can be utilized for predicting power during initial resource assessment and designing of small systems if very good accuracy is not desired. $4 \mathrm{PL}$ and $5 \mathrm{PL}$ parametric models can follow the actual shape of the power curve more accurately. These novel methods can result in reduced power prediction errors and can be applied for power and energy assessment during design of large systems and forecasting of power for energy trading where good accuracy is a crucial requirement.

(ii) The deterministic methods which use manufacturer's data for modelling are suitable for single turbines and not appropriate for modelling a group of turbines. The probabilistic methods which consider the variation of both power and wind speed are suitable for modelling power curve for a fleet of turbines.

(iii) Power curve models extracted from actual data of wind farms can incorporate actual conditions at a site and are suitable for modelling a group of turbines. These curves can be derived from the available data by parametric and nonparametric methods.

(iv) The parametric models derived from actual wind farm data used in the literature include linear segmented and 4PL and 5PL models. Nonparametric methods used are neural networks, clustering methods, data mining, ANFIS, and copula models. Data mining techniques can offer good results as the data available from the wind farms is voluminous and frequent updating of data is easier. ANN and ANFIS models perform well for power prediction and online monitoring applications. These curves derived from actual data can help in minimizing power prediction errors.

(v) The 4PL and data mining technique based models extracted from actual data of wind farms have been analyzed in the literature for their application in online monitoring. It is indicated that the monitoring of the power curves can be used to detect anomalies and statistical analysis of the outlier data can give indications of the specific reason of anomaly. Application of 5PL model for online monitoring of curve is not yet researched.

(vi) The wind power output of a turbine can be affected by various faults/anomalies or underperformance of the turbine, such as blade faults and yaw and pitch system faults. Different types of faults affect the turbine system differently and cause the power curve to depart from the expected value in a different way. Tools which can characterize and quantify these departures can aid in early identification of faults. Likely link between copula statistics and WT faults/anomalies is indicated in the literature should be investigated. Further research should also focus on considering the joint probability distribution of these variables.

(vii) Applications of advanced algorithms for developing improved parametric and nonparametric methods need to be explored. 


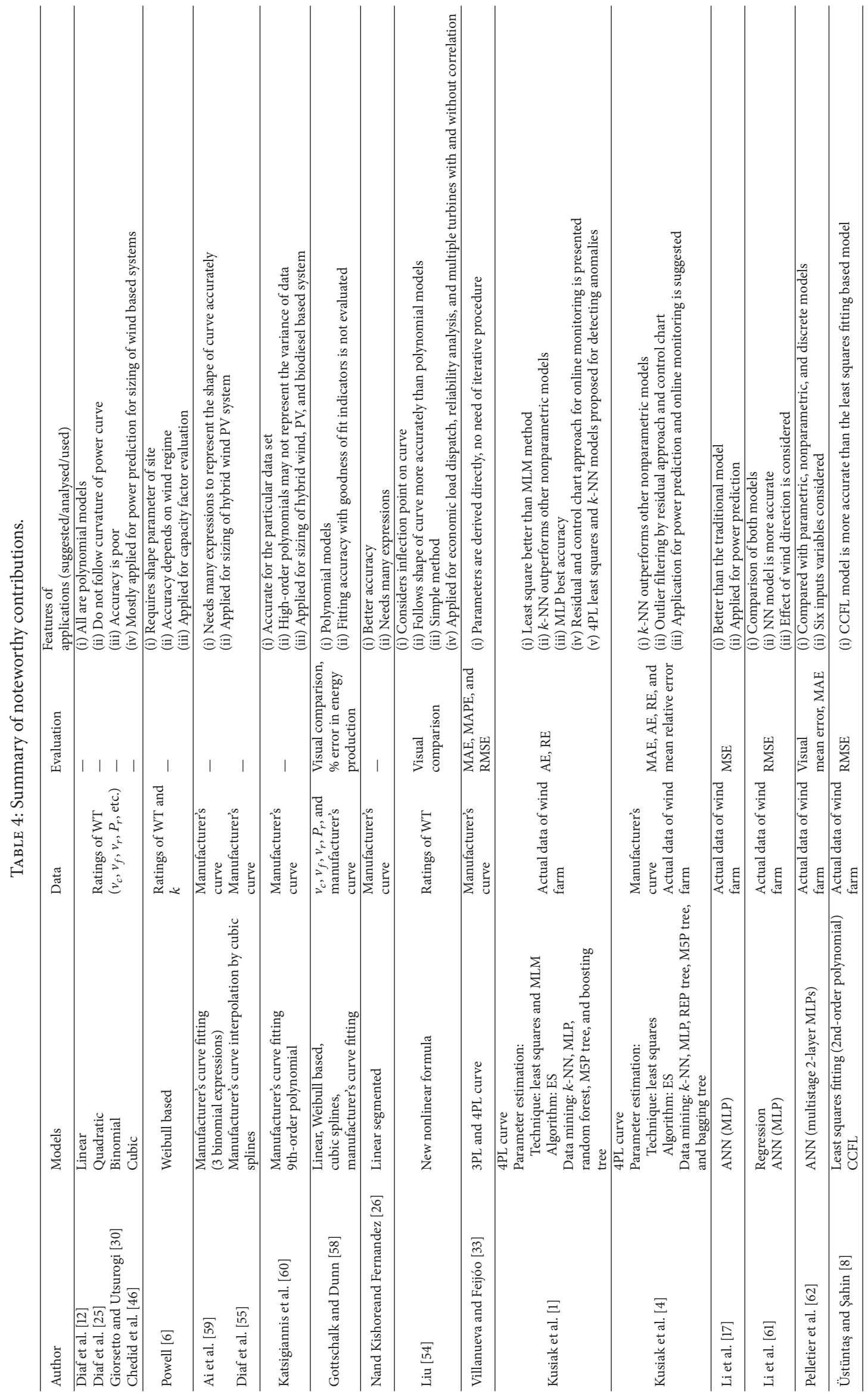




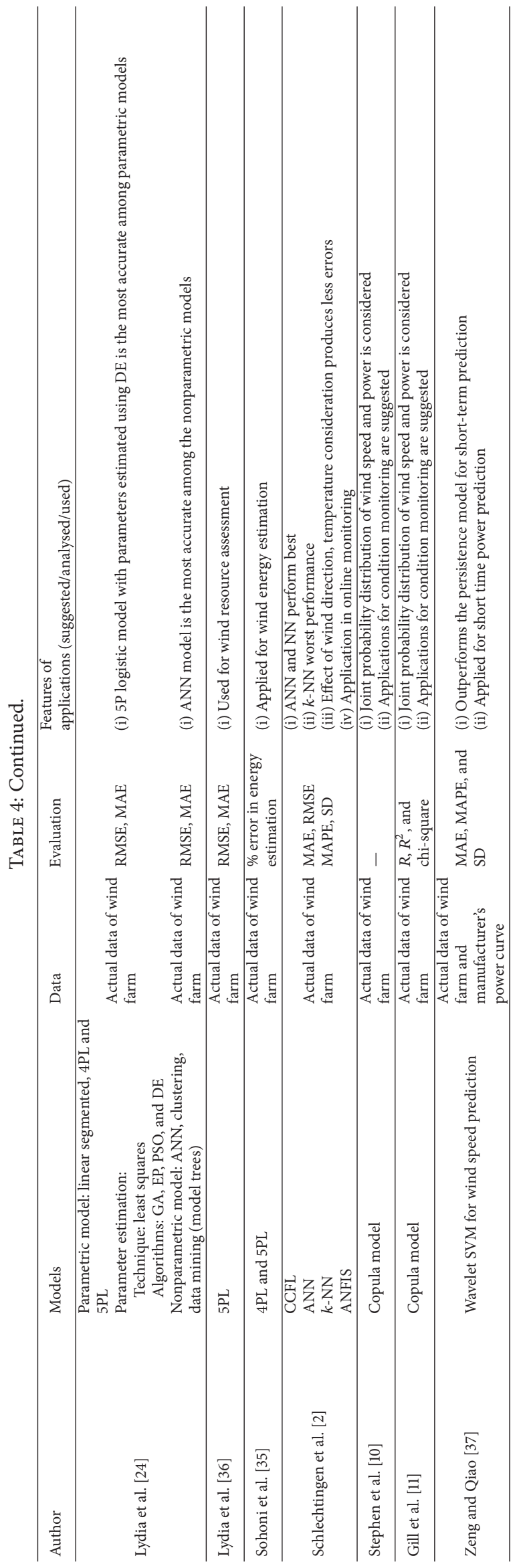


TABLE 5: Comparison of modelling methods.

\begin{tabular}{|c|c|c|c|c|}
\hline Models & $\begin{array}{l}\text { Data required } \\
\text { for modelling }\end{array}$ & Merits & Demerits & Applications \\
\hline $\begin{array}{l}\text { Polynomial } \\
\text { models } \\
\text { (linear, } \\
\text { quadratic, } \\
\text { binomial, cubic, } \\
\text { and Weibull } \\
\text { based) }\end{array}$ & $\begin{array}{l}v_{c}, v_{f}, v_{r} \text {, and } P_{r} \\
\text { of turbine }\end{array}$ & $\begin{array}{l}\text { (i) Simplicity } \\
\text { (ii) Limited data required } \\
\text { (iii) Parameter calculation is easy }\end{array}$ & $\begin{array}{l}\text { (i) Do not follow curvature of } \\
\text { power curve } \\
\text { (ii) Accuracy is poor } \\
\text { (iii) Sometimes more than one } \\
\text { expression are used to } \\
\text { describe the shape of curve }\end{array}$ & $\begin{array}{l}\text { Suitable for power prediction } \\
\text { and energy estimation during } \\
\text { initial resource assessment } \\
\text { and designing of small systems }\end{array}$ \\
\hline
\end{tabular}

(i) Requires manufacturer's

$\begin{array}{lll}\text { Manufacturer's Manufacturer's } & \text { (i) Need less data }\end{array}$

\begin{tabular}{|c|c|c|c|}
\hline Cubic splines & $\begin{array}{l}\text { Manufacturer's } \\
\text { curve }\end{array}$ & (i) Exact fit & $\begin{array}{l}\text { (i) Variance of data is not } \\
\text { taken into account }\end{array}$ \\
\hline
\end{tabular}

(i) Consider inflection point on Manufacturer's curve; hence shape of curve is 4PL model curve, actual represented more accurately than data of wind the earlier models farm (ii) One expression is required

Manufacturer's (i) Consider inflection point on curve curve and asymmetry of curve is modelled more accurate than the $\begin{array}{ll}\text { wind farm } & \text { earlier and 4PL models } \\ & \text { (ii) One expression is required }\end{array}$

$\begin{array}{lll}\text { ANN } & \begin{array}{l}\text { Actual data of } \\ \text { wind farm }\end{array} & \begin{array}{l}\text { (i) Found to be accurate than other } \\ \text { methods }\end{array}\end{array}$
wind farm power curve data

(ii) Fairly accurate

(iii) Many expressions may be required for accurate

representation of curve

Suitable for power prediction and energy estimation during initial resource assessment and designing of small systems

(i) Asymmetry of curve not modelled

(i) Parameter estimation is

difficult

\section{Power prediction}

Online monitoring; further research on power prediction during design and power forecasting applications is required

Further research on power prediction during design and power forecasting and online monitoring applications is required

Wind power assessment for sizing and power forecasting, and online monitoring applications, suitable for group of turbines

Wind power assessment for sizing and power forecasting, and online monitoring applications, suitable for group of turbines number of cluster centres

Wind power assessment for

(i) Accuracy depends on value sizing and power forecasting,

$\begin{array}{llll}k \text {-NN } & \begin{array}{l}\text { Actual data of } \\ \text { wind farm }\end{array} & \begin{array}{l}\text { (i) Performance variable in different } \\ \text { studies }\end{array} & \begin{array}{l}\text { of } k \\ \text { (ii) Less training time as } \\ \text { instance based scheme }\end{array}\end{array}$

prediction, and

online monitoring

applications, suitable for group of turbines

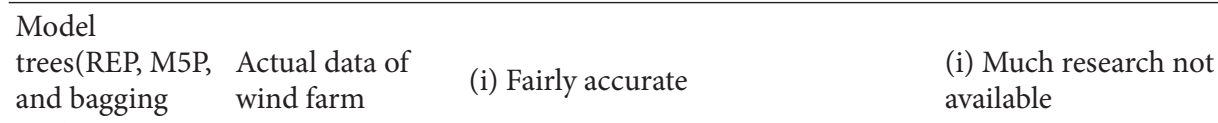

Applicability in power prediction and online monitoring to be explored

tree)
(i) Integrates best features of fuzzy
systems and neural networks

$\begin{array}{lll}\text { ANFIS } & \text { Actual data of } & \begin{array}{l}\text { (ii) Accurate method } \\ \text { wind farm }\end{array} \\ & \text { (iii) Fewer parameters required in } \\ \text { training therefore faster training } & \end{array}$

(iv) Tunable membership functions

\section{(i) Considers joint probability}

distribution of wind speed and $\begin{array}{lll}\text { Copula model } & \begin{array}{l}\text { Actual data of } \\ \text { wind farm }\end{array} & \begin{array}{l}\text { power } \\ \text { (ii) Includes measures of } \\ \text { uncertainty in performance }\end{array}\end{array}$ estimates
Wind power assessment for sizing and power forecasting for energy trading Online monitoring applications, suitable for group of turbines (i) Computational complexity

(i) Needs advanced method for parameter estimation of marginals
Applications for condition monitoring to be investigated 


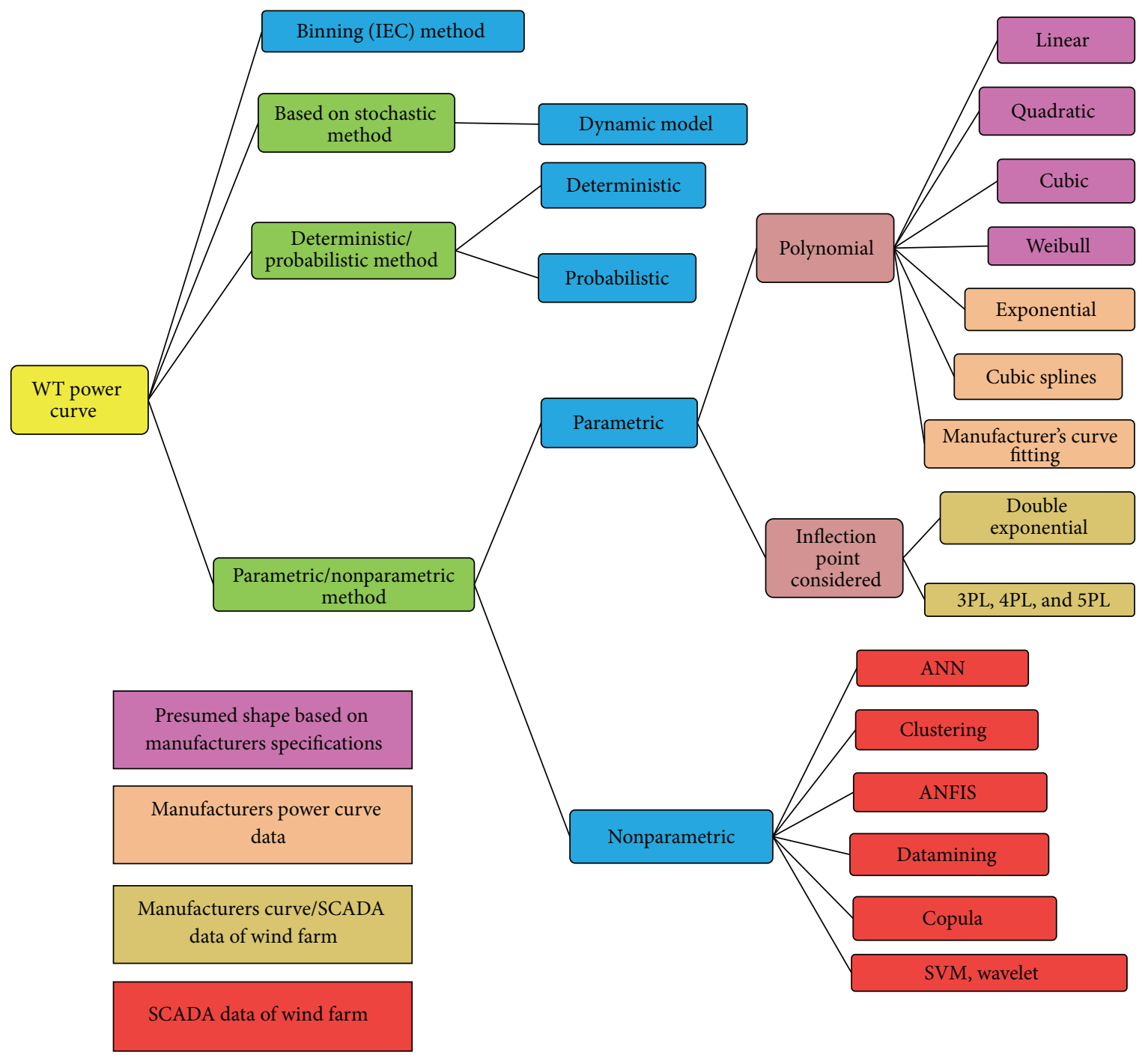

FIgURE 3: Wind turbine power curve models.

(viii) Appropriate evaluation of the developed models is a very important requirement in modelling. The right choice of an evaluation metric is important and depends on the data and analysis requirements. Models developed in the literature have used different performance metrics. The reviewed articles do not highlight the reason of preferring a particular criterion for evaluation. Different statistical measures can have different interpretations and appropriate selection of error metrics is crucial for analysis of the models. Moreover these models will ultimately be used in wind energy applications; therefore it is not appropriate to judge their suitability on the basis of goodness of fit parameters alone, but it should also be examined how successfully these models can be employed for the particular applications.

(ix) Power curves of wind turbines provided by the manufacturers are used for power prediction in most of the wind energy applications. These curves are developed under standard test conditions. The IEC 61400-12-1 is the most accepted standard for power curve measurement of single wind turbines. The wind conditions at the practical sites can be different from those at the test site. IEC curve may not always represent the wind conditions of other sites. Further research should focus on development of site specific power curves.

(x) The discrete model prescribed in IEC 61400-12 is simple, but a large amount of data is required to develop a reliable model.

(xi) The stochastic model that is proposed in some works is independent of turbulence intensity but does not include the effect of other influencing parameters.

(xii) Future works should also include the effect of various influencing parameters on the power curves. 


\section{Conclusions}

Accurate modelling of WT power curves is crucial for successful design and operation of any wind energy conversion system. This paper presented an overview of different approaches used for modelling of wind turbine power curve. There are several methods of modelling which have their own advantages and disadvantages. Polynomial approximation based power curve models which have been used widely are simple to use and can be utilized for predicting power during initial resource assessment and designing of small systems. The four- and five-parameter logistic function based power curve models which consider the inflection point on these curves are promising methods which can help in reduction of power prediction errors and improved performance in online monitoring of these curves. Also most of the models in earlier works are developed from manufacturers curves of wind turbines. However, the manufacturer supplied curves are turbine specific and represent their behaviour under standard test conditions. They can be applied for power prediction of single turbines and for sites with steady winds. Improved models are required which can represent the conditions at large wind farms with a group of turbines installed and sites having complex terrains. Power curves derived from actual wind speed and output power data from wind farms can take into account various site specific factors resulting in better models. A wind farm's SCADA data is a valuable resource which can be exploited for this purpose. Nonparametric methods of power curve modelling used in the literature include neural networks, clustering, data mining, ANFIS, and copula models. The nonparametric methods are suitable for extracting models from large data. Moreover, these models can incorporate the effect of parameters other than wind speed on the power curves more easily than the parametric models. Literature survey reveals that ANN and ANFIS nonparametric methods perform well among other models for power prediction and online monitoring applications. Further research should focus on development of site specific power curves. Future models should be able to minimize the prediction errors and should be suitable for online monitoring of turbines. Methods which can quantify the power curve departures from expected values for identification of turbine faults should be explored. As the power output of wind turbines is strongly dependent on wind speed of a potential wind farm site, selection of appropriate wind speed model along with the power curve model is an important requirement for accurate prediction of wind farm output. Different wind speed modelling techniques have also been reviewed briefly in this paper. It can be concluded that selection of appropriate model, solution technique, and proper algorithms for a particular application is important for efficient modelling and can contribute significantly to developing reliable and efficient wind energy based power system.

\section{Nomenclature}

P: $\quad$ Power output of wind turbine (W)

$v$ : Wind speed $(\mathrm{m} / \mathrm{s})$

$A_{w}$ : Area swept by the rotor blades $\left(\mathrm{m}^{2}\right)$

$\rho: \quad$ Air density $\left(\mathrm{kg} / \mathrm{m}^{3}\right)$

$\lambda$ : $\quad$ Tip speed ratio

$\beta$ : $\quad$ Pitch angle (degree)

$C_{p}$ : Power coefficient of wind turbine

$k$ : $\quad$ Shape parameter Weibull PDF

$c$ : Scale parameter Weibull PDF

$v_{c}$ : Cut-in wind speed of turbine $(\mathrm{m} / \mathrm{s})$

$v_{r}:$ Rated wind speed of turbine $(\mathrm{m} / \mathrm{s})$

$v_{f}$ : Cut-off (or furling) wind speed of turbine $(\mathrm{m} / \mathrm{s})$

$P_{r}:$ Rated power of wind turbine (W)

$\eta_{w}$ : The efficiency of WTG and the corresponding converter

$\theta$ : Vector parameter of parametric models.

\section{Competing Interests}

The authors declare that there is no conflict of interests regarding the publication of this paper.

\section{References}

[1] A. Kusiak, H. Zheng, and Z. Song, "On-line monitoring of power curves," Renewable Energy, vol. 34, no. 6, pp. 1487-1493, 2009.

[2] M. Schlechtingen, I. F. Santos, and S. Achiche, "Using datamining approaches for wind turbine power curve monitoring: a comparative study," IEEE Transactions on Sustainable Energy, vol. 4, no. 3, pp. 671-679, 2013.

[3] S. Mathew, Wind Energy-Fundamentals, Resource Analysis and Economics, Springer, Berlin, Germany, 2006.

[4] A. Kusiak, H. Zheng, and Z. Song, "Models for monitoring wind farm power," Renewable Energy, vol. 34, no. 3, pp. 583-590, 2009.

[5] F. A. L. Jowder, "Wind power analysis and site matching of wind turbine generators in Kingdom of Bahrain," Applied Energy, vol. 86, no. 4, pp. 538-545, 2009.

[6] W. R. Powell, "An analytical expression for the average output power of a wind machine," Solar Energy, vol. 26, no. 1, pp. 7780, 1981.

[7] T.-P. Chang, F.-J. Liu, H.-H. Ko, S.-P. Cheng, L.-C. Sun, and S.C. Kuo, "Comparative analysis on power curve models of wind turbine generator in estimating capacity factor," Energy, vol. 73, pp. 88-95, 2014.

[8] T. Üstüntaş and A. D. Şahin, "Wind turbine power curve estimation based on cluster center fuzzy logic modeling," Journal of Wind Engineering and Industrial Aerodynamics, vol. 96, no. 5, pp. 611-620, 2008.

[9] J.-Y. Park, J.-K. Lee, K.-Y. Oh, and J.-S. Lee, "Development of a novel power curve monitoring method for wind turbines and its field tests," IEEE Transactions on Energy Conversion, vol. 29, no. 1, pp. 119-128, 2014.

[10] B. Stephen, S. J. Galloway, D. McMillan, D. C. Hill, and D. G. Infield, "A copula model of wind turbine performance," IEEE Transactions on Power Systems, vol. 26, no. 2, pp. 965-966, 2011. 
[11] S. Gill, B. Stephen, and S. Galloway, "Wind turbine condition assessment through power curve copula modeling," IEEE Transactions on Sustainable Energy, vol. 3, no. 1, pp. 94-101, 2012.

[12] S. Diaf, M. Belhamel, M. Haddadi, and A. Louche, "Technical and economic assessment of hybrid photovoltaic/wind system with battery storage in Corsica island," Energy Policy, vol. 36, no. 2, pp. 743-754, 2008.

[13] L. Horváth, T. Panza, and N. Karadža, "The influence of high wind hysteresis effect on wind turbine power production at Bura-dominated site," in Proceedings of the European Wind Energy Conference and Exhibition (EWEC '07), pp. 1017-1022, Milan, Italy, May 2007.

[14] T. Jin and Z. Tian, "Uncertainty analysis for wind energy production with dynamic power curves," in Proceedings of the IEEE 11th International Conference on Probabilistic Methods Applied to Power Systems (PMAPS '10), pp. 745-750, IEEE, Singapore, June 2010.

[15] J. R. McLean, "WP2.6-Equivalent wind power curves," Tech. Rep. EIE/06/022/SI2.442659, 2008.

[16] E. Hedevang, "Wind turbine power curves incorporating turbulence intensity," Wind Energy, vol. 17, no. 2, pp. 173-195, 2014.

[17] S. Li, D. C. Wunsch, E. A. O’Hair, and M. G. Giesselmann, "Using neural networks to estimate wind turbine power generation," IEEE Transactions on Energy Conversion, vol. 16, no. 3, pp. 276-282, 2001.

[18] Z. O. Olaofe and K. A. Folly, "Wind energy analysis based on turbine and developed site power curves: a case-study of Darling City," Renewable Energy, vol. 53, pp. 306-318, 2013.

[19] International standard IEC 61400-12-1, Wind turbines- Power performance measurement of electricity producing wind turbines, 2005.

[20] H. Mellinghoff, Development of Power Curve Measurement Standards, DEWEK 2012: 11, Deutsche Windenergie-Konferenz, Bremen, Germany, 2012.

[21] S. A. Akdağ and A. Dinler, "A new method to estimate Weibull parameters for wind energy applications," Energy Conversion and Management, vol. 50, no. 7, pp. 1761-1766, 2009.

[22] J. A. Carta, P. Ramírez, and S. Velázquez, "A review of wind speed probability distributions used in wind energy analysis. Case studies in the Canary Islands," Renewable and Sustainable Energy Reviews, vol. 13, no. 5, pp. 933-955, 2009.

[23] V. Lo Brano, A. Orioli, G. Ciulla, and S. Culotta, "Quality of wind speed fitting distributions for the urban area of Palermo, Italy," Renewable Energy, vol. 36, no. 3, pp. 1026-1039, 2011.

[24] M. Lydia, A. I. Selvakumar, S. S. Kumar, and G. E. P. Kumar, "Advanced algorithms for wind turbine power curve modeling," IEEE Transactions on Sustainable Energy, vol. 4, no. 3, pp. 827835, 2013.

[25] S. Diaf, G. Notton, M. Belhamel, M. Haddadi, and A. Louche, "Design and techno-economical optimization for hybrid PV/ wind system under various meteorological conditions," Applied Energy, vol. 85, no. 10, pp. 968-987, 2008.

[26] L. Nand Kishore and E. Fernandez, "Reliability well-being assessment of PV-wind hybrid system using Monte Carlo simulation," in Proceedings of the International Conference on Emerging Trends in Electrical and Computer Technology (ICETECT '11), pp. 63-68, Tamil Nadu, India, March 2011.

[27] P. Milan, M. Wachter, and J. Peinke, "Stochastic modeling and performance monitoring of wind farm power production," Journal of Renewable and Sustainable Energy, vol. 6, no. 3, Article ID 033119, 2014.
[28] E. Anahua, F. Böttcher, S. Barth, J. Peinke, and M. Lange, "Stochastic analysis of the power output for a wind turbine," in Proceedings of the European Wind Energy Conference (EWEC '04), London, UK, November 2004.

[29] E. Anahua, S. Barth, and J. Peinke, "Markovian power curves for wind turbines," Wind Energy, vol. 11, no. 3, pp. 219-232, 2008.

[30] P. Giorsetto and K. F. Utsurogi, "Development of a new procedure for reliability modeling of wind turbine generators," IEEE Transactions on Power Apparatus and Systems, vol. 102, no. 1, pp. 134-143, 1983.

[31] M. K. Deshmukh and S. S. Deshmukh, "Modeling of hybrid renewable energy systems," Renewable and Sustainable Energy Reviews, vol. 12, no. 1, pp. 235-249, 2008.

[32] E. Sainz, A. Llombart, and J. J. Guerrero, "Robust filtering for the characterization of wind turbines: improving its operation and maintenance," Energy Conversion and Management, vol. 50, no. 9, pp. 2136-2147, 2009.

[33] D. Villanueva and A. E. Feijóo, "Reformulation of parameters of the logistic function applied to power curves of wind turbines," Electric Power Systems Research, vol. 137, pp. 51-58, 2016.

[34] D. Rodbard, "Statistical quality control and routine data processing for radioimmunoassays and immunoradiometric assays," Clinical Chemistry, vol. 20, no. 10, pp. 1255-1270, 1974.

[35] V. Sohoni, S. C. Gupta, and R. K. Nema, "A comparative analysis of wind speed probability distributions for wind power assessment of four sites," Turkish Journal of Electrical Engineering and Computer Sciences, 2016.

[36] M. Lydia, S. Suresh Kumar, A. Immanuel Selvakumar, and G. Edwin Prem Kumar, "Wind resource estimation using wind speed and power curve models," Renewable Energy, vol. 83, pp. 425-434, 2015.

[37] J. Zeng and W. Qiao, "Short-term wind power prediction using a wavelet support vector machine," IEEE Transactions on Sustainable Energy, vol. 3, no. 2, pp. 255-264, 2012.

[38] Curve fitting toolbox, for use with MATLAB, User's Guide, Version 1.The Mathworks, 2002.

[39] H. Yang, L. Lu, and W. Zhou, "A novel optimization sizing model for hybrid solar-wind power generation system," Solar Energy, vol. 81, no. 1, pp. 76-84, 2007.

[40] L. Xu, X. Ruan, C. Mao, B. Zhang, and Y. Luo, "An improved optimal sizing method for wind-solar-battery hybrid power system," IEEE Transactions on Sustainable Energy, vol. 4, no. 3, pp. 774-785, 2013.

[41] X. Liu and W. Xu, "Minimum emission dispatch constrained by stochastic wind power availability and cost," IEEE Transactions on Power Systems, vol. 25, no. 3, pp. 1705-1713, 2010.

[42] Y. M. Atwa, E. F. El-Saadany, M. M. A. Salama, R. Seethapathy, M. Assam, and S. Conti, "Adequacy evaluation of distribution system including wind/solar DG during different modes of operation," IEEE Transactions on Power Systems, vol. 26, no. 4, pp. 1945-1952, 2011.

[43] R. Karki, P. Hu, and R. Billinton, "Reliability evaluation considering wind and hydro power coordination," IEEE Transactions on Power Systems, vol. 25, no. 2, pp. 685-693, 2010.

[44] P. Wang, Z. Gao, and L. Bertling, "Operational adequacy studies of power systems with wind farms and energy storages," IEEE Transactions on Power Systems, vol. 27, no. 4, pp. 2377-2384, 2012.

[45] L. Lu, H. Yang, and J. Burnett, "Investigation on wind power potential on Hong Kong islands - an analysis of wind power and wind turbine characteristics," Renewable Energy, vol. 27, no. 1, pp. 1-12, 2002. 
[46] R. Chedid, H. Akiki, and S. Rahman, "A decision support technique for the design of hybrid solar-wind power systems," IEEE Transactions on Energy Conversion, vol. 13, no. 1, pp. 7683, 1998.

[47] L. Wang and C. Singh, "Adequacy-based design of a hybrid generating system including intermittent sources using constrained particle swarm optimization," IEEE Transactions on Power Systems, vol. 27, no. 4, pp. 2377-2383, 2007.

[48] A. K. Kaviani, G. H. Riahy, and S. M. Kouhsari, "Optimal design of a reliable hydrogen-based stand-alone wind/PV generating system, considering component outages," Renewable Energy, vol. 34, no. 11, pp. 2380-2390, 2009.

[49] B. S. Borowy and Z. M. Salameh, "Optimum photovoltaic array size for a hybrid wind/PV system," IEEE Transactions on Energy Conversion, vol. 9, no. 3, pp. 482-488, 1994.

[50] B. S. Borowy and Z. M. Salameh, "Methodology for optimally sizing the combination of a battery bank and PV array in a wind/PV hybrid system," IEEE Transactions on Energy Conversion, vol. 11, no. 2, pp. 367-375, 1996.

[51] M. G. Khalfallah and A. M. Koliub, "Suggestions for improving wind turbines power curves," Desalination, vol. 209, no. 1-3, pp. 221-229, 2007.

[52] C. Carrilo, A. F. O. Montaño, J. Cidras, and D. Dorado, "Review of power curve modelling for wind turbines," Renewable and Sustainable Energy Reviews, vol. 21, pp. 572-581, 2013.

[53] S. Shokrzadeh, M. Jafari Jozani, and E. Bibeau, "Wind turbine power curve modeling using advanced parametric and nonparametric methods," IEEE Transactions on Sustainable Energy, vol. 5, no. 4, pp. 1262-1269, 2014.

[54] X. Liu, "An improved interpolation method for wind power curves," IEEE Transactions on Sustainable Energy, vol. 3, no. 3, pp. 528-534, 2012.

[55] S. Diaf, D. Diaf, M. Belhamel, M. Haddadi, and A. Louche, "A methodology for optimal sizing of autonomous hybrid PV/wind system," Energy Policy, vol. 35, no. 11, pp. 5708-5718, 2007.

[56] F. O. Hocaoğlu, Ö. N. Gerek, and M. Kurban, "A novel hybrid (wind-photovoltaic) system sizing procedure," Solar Energy, vol. 83, no. 11, pp. 2019-2028, 2009.

[57] V. Thapar, G. Agnihotri, and V. K. Sethi, "Critical analysis of methods for mathematical modelling of wind turbines," Renewable Energy, vol. 36, no. 11, pp. 3166-3177, 2011.

[58] P. G. Gottschalk and J. R. Dunn, “The five-parameter logistic: a characterization and comparison with the four-parameter logistic," Analytical Biochemistry, vol. 343, no. 1, pp. 54-65, 2005.

[59] B. Ai, H. Yang, H. Shen, and X. Liao, "Computer-aided design of PV/wind hybrid system," Renewable Energy, vol. 28, no. 10, pp. 1491-1512, 2003.

[60] Y. A. Katsigiannis, P. S. Georgilakis, and E. S. Karapidakis, "Hybrid simulated annealing-tabu search method for optimal sizing of autonomous power systems with renewables," IEEE Transactions on Sustainable Energy, vol. 3, no. 3, pp. 330-338, 2012.

[61] S. Li, D. C. Wunsch, E. O’Hair, and M. G. Giesselmann, “Comparative analysis of regression and artificial neural network models for wind turbine power curve estimation," Journal of Solar Energy Engineering, vol. 123, no. 4, pp. 327-332, 2001.

[62] F. Pelletier, C. Masson, and A. Tahan, "Wind turbine power curve modelling using artificial neural network," Renewable Energy, vol. 89, pp. 207-214, 2016.
[63] M. Schlechtingen and I. Ferreira Santos, "Comparative analysis of neural network and regression based condition monitoring approaches for wind turbine fault detection," Mechanical Systems and Signal Processing, vol. 25, no. 5, pp. 1849-1875, 2011.

[64] Y. Wang, D. G. Infield, B. Stephen, and S. J. Galloway, "Copulabased model for wind turbine power curve outlier rejection," Wind Energy, vol. 17, no. 11, pp. 1677-1688, 2014.

[65] L. Zheng, W. Hu, and Y. Min, "Raw wind data preprocessing: a data-mining approach," IEEE Transactions on Sustainable Energy, vol. 6, no. 1, pp. 11-19, 2015.

[66] National Renewable Energy Laboratory (NREL) western data set, station ID 2 dataset year 2006, http://wind.nrel.gov/ Web_nrel/.

[67] S. R. Jang, C.-T. Sun, and E. Mizutani, Neuro-Fuzzy and Soft Computing-a Computational Approach to Learning and Machine Intelligence, PHI ltd, New Delhi, India, 2003.

[68] S. R. Jang, C.-T. Sun, and E. Mizutani, Neuro-Fuzzy and Soft Computing-A Computational Approach to Learning and Machine Intelligence, PHI ltd, New Delhi, India, 2003.

[69] M. S. Mohan Raj, M. Alexander, and M. Lydia, "Modeling of wind turbine power curve," in Proceedings of the IEEE PES Conference on Innovative Smart Grid Technologies-India, Kollam, India, December 2011.

[70] S. L. Chiu, "Fuzzy model identification based on cluster estimation," Journal of Intelligent and Fuzzy Systems, vol. 2, pp. 267278, 1994.

[71] J. Han and M. Kamber, Data Mining: Concepts and Techniques, Morgan Kaufmann, San Francisco, Calif, USA, 2006.

[72] A. M. Prasad, L. R. Iverson, and A. Liaw, "Newer classification and regression tree techniques: bagging and random forests for ecological prediction," Ecosystems, vol. 9, no. 2, pp. 181-199, 2006.

[73] I. H. Witten and E. Frank, Data Mining: Practical Machine Learning Tools and Techniques, Morgan Kaufmann, San Francisco, Calif, USA, 2nd edition, 2005.

[74] M. Lydia, S. S. Kumar, A. I. Selvakumar, and G. E. Prem Kumar, "A comprehensive review on wind turbine power curve modeling techniques," Renewable and Sustainable Energy Reviews, vol. 30, pp. 452-460, 2014.

[75] S. A. Akdağ and Ö. Gler, "A comparison of wind turbine power curve models," Energy Sources, Part A: Recovery, Utilization and Environmental Effects, vol. 33, no. 24, pp. 2257-2263, 2011. 

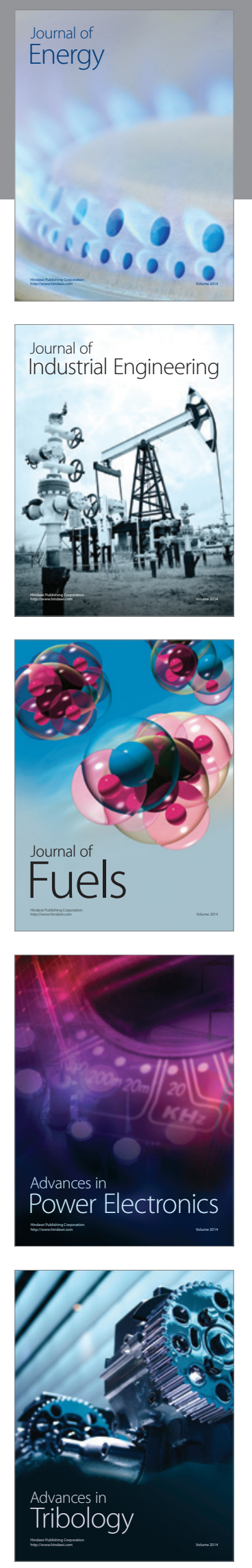
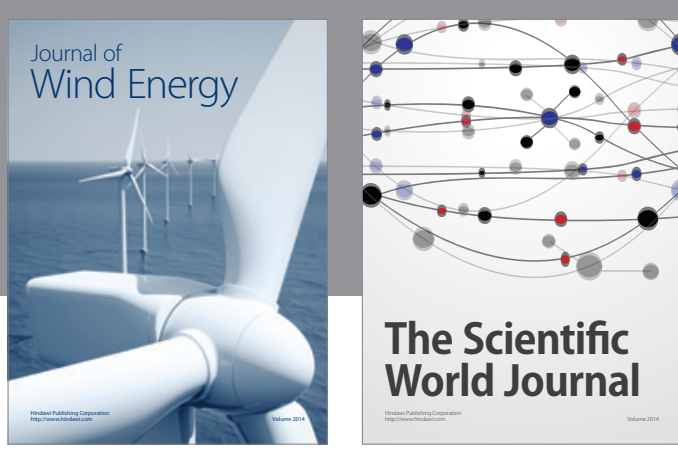

The Scientific World Journal
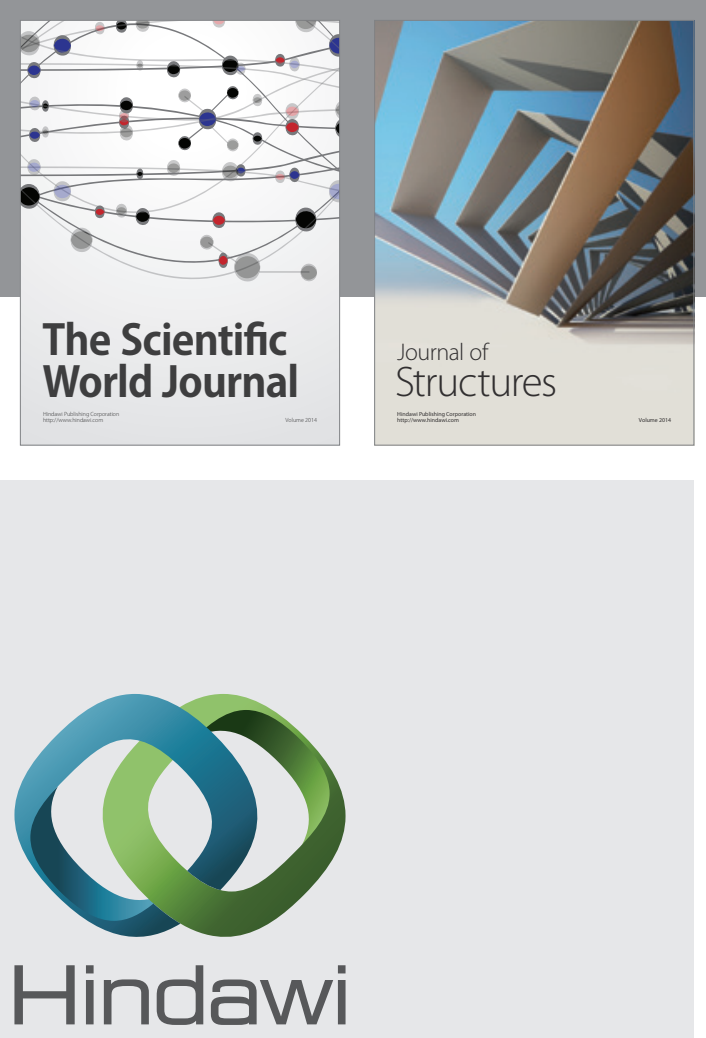

Submit your manuscripts at

http://www.hindawi.com
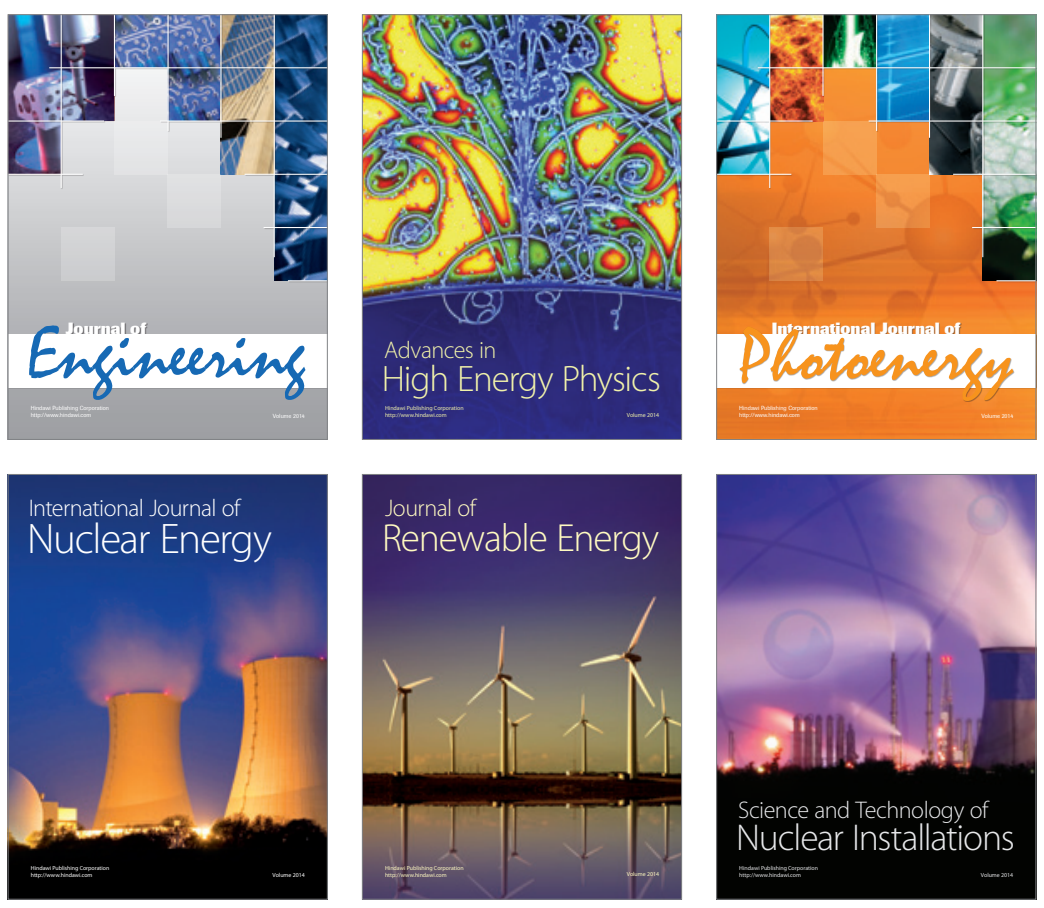
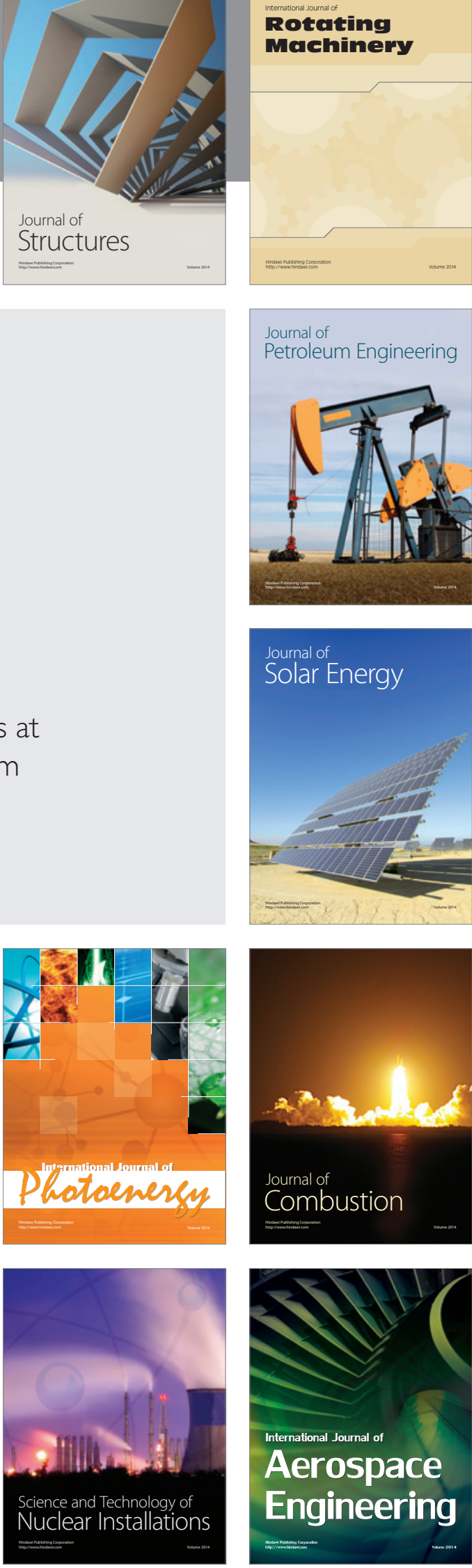